\title{
Hubungan antara fraktur maksilofasial dengan terjadinya lesi intrakranial
}

\author{
Anton Tanuhendrata \\ Mendy Hatibie \\ Maximillian Ch. Oley \\ Eko Prasetyo
}

\author{
Bagian Bedah Fakultas Kedokteran Universitas Sam Ratulangi Manado \\ Email: anton.andrian.tanu@gmail.com
}

\begin{abstract}
Maxillofacial structure is an unprotected part of the head and is easily exposed to blunt trauma. This structure functions as a safety cushion for the brain when a trauma occures. This study was conducted at Prof. Dr. R. D. Kandou Hospital Manado and aimed to obtain the relationship between maxillofacial fracture and intracranial lesion. Subjects were patients at the emergency unit with traffic accident associated with maxillofacial fracture with or without intracranial lelsion. GCS examination and CT scan of the head were performed to evaluate the intracranial lesion and the maxillofacial fracture (mild, moderate, or severe depended on the type of fracture). Data were tabulated and analyzed with Spearman correlation test using SPSS 2.2 program. The results showed that there were 50 patients with maxilllofacial injury, consisted of: 19 patients with mild injury, 25 patients with moderate injury, and 6 patients with severe injury. There were 13 patients with intracranial lesion and 37 patients without intracranial lesion. The Spearman correlation test showed an $\mathrm{X}^{2}=32,60$ and a $P<0.0001$. Conclusion: There was a significant correlation between maxillofacial fracture and intracranial lesion.
\end{abstract}

Keywords: maxillofacial fracture, intracranial lesion

\begin{abstract}
Abstrak: Struktur maksilofasial merupakan bagian dari tubuh yang tidak terlindungi, mudah terpapar oleh trauma tumpul, dan merupakan bantal pengaman untuk otak saat trauma terjadi. Penelitian ini bertujuan untuk mendapatkan hubungan antara fraktur maksilofasial dengan lesi intracranial dan dilakukan di RSUP Prof. Dr. R. D. Kandou Manado. Subyek penelitian ialah pasien yang datang ke unit gawat darurat yang mengalami kecelakaan lalu lintas dengan fraktur maksilofasial serta ada atau tidaknya lesi intrakranial. Pemeriksaan GCS serta CT scan kepala dilakukan untuk menilai lesi intrakranial sekaligus menilai fraktur maksilofasial (ringan, sedang, atau berat, tergantung dari jenis fraktur). Data ditabulasi dan diuji kemaknaannya dengan korelasi Spearman menggunakan program SPSS 2.2. Hasil penelitian memperlihatkan dari 50 pasien dengan cedera maksilofasial didapatkan: 19 pasien cedera ringan, 25 pasien cedera sedang, dan 6 pasien cedera berat. Terdapat 13 pasien yang disertai lesi intrakranial, sedangkan yang tanpa lesi intrakranial sebanyak 37 pasien. Uji statistik mendapatkan nilai $\mathrm{X}^{2}=32,60$ dengan $P<0,0001$ yang menunjukkan hubungan bermakna antara fraktur maksilofasial dan lesi intrakranial. Simpulan: Terdapat hubungan bermakna antara fraktur maksilofasial dan lesi intrakranial.
\end{abstract}

Kata kunci: Fraktur maksilofasial, lesi intrakranial

Secara topografis, wajah merupakan bagian tubuh yang tidak terlindungi dan mudah terpapar trauma sehingga cedera wajah merupakan merupakan jenis cedera yang sangat sering dijumpai. Fraktur tulang wajah (maksilofasial) paling 
sering disebabkan oleh kecelakaan lalulintas dan perkelahian, sehingga umumnya merupakan kasus multi-trauma. Meskipun fraktur maksilofasial sendiri jarang membutuhkan tindakan bedah segera, cedera strukur otak yang menyertai sering merupakan kasus bedah emergensi. ${ }^{1}$

Cedera otak traumatik merupakan salah satu penyebab tersering kematian dan disabilitas di dunia. Hal ini berhubungan dengan tingginya angka kejadian fraktur tulang wajah dalam berbagai kombinasi. ${ }^{2}$ Penelitian oleh Fawzy dan Sudjatmiko (2007) di RSCM Jakarta menemukan ratarata 14,3 kasus fraktur maksilofasial setiap bulannya; $31,4 \%$ diantaranya disertai cedera otak serius. Penelitian tersebut menemukan fraktur mandibula yang tersering $(31,30 \%)$, diikuti oleh fraktur maksila $(23,48 \%)$. Penelitian ini menyimpulkan bahwa adanya fraktur tulang wajah sepertiga tengah mengurangi resiko terjadinya cedera otak yang lebih berat, sementara fraktur mandibula menambah resiko terjadinya cedera otak yang lebih berat. ${ }^{3}$ Cerwinzki et al. ${ }^{4}$ menemukan bahwa pada pasien dengan fraktur mandibula, $40 \%$ berhubungan dengan cedera kepala dan $35 \%$ berhubungan dengan lesi intrakranial. Di Manado belum pernah dilaporkan bagaimana hubungan antara fraktur maksilofasial dengan lesi intrakranial.

Pada tulang wajah terdapat ronggarongga sinus yang membentuk karakter wajah seseorang yang merupakan bumper atau bantalan angin untuk melindungi otak dari benturan langsung. Bantalan paling besar terletak pada bagian tengah wajah yang mempunyai paling banyak sinus. Bila benturan terjadi pada bagian bawah dari wajah, maka secara otomatis otak mendapat perlindungan paling maksimal dikarenakan daya yang datang ke otak telah dihambat oleh hampir seluruh bantalan pada wajah.

Penelitian ini bertujuan untuk mendapatkan hubungan antara fraktur maksilofasial dengan adanya lesi intrakranial dengan asumsi bantalan tersebut dapat berfungsi melindungi otak dari trauma. ${ }^{5}$

\section{METODE PENELITIAN}

Subyek penelitian ialah pasien cedera maksilofasial akibat trauma tumpul yang berusia 16-50 tahun. Pada pasien cedera maksilofasial yang disertai cedera kepala dilakukan pemeriksaan GCS dan CT scan kepala untuk menilai lesi intrakranial sekaligus menilai adanya fraktur pada maksilofasial. Data yang diperoleh ditabulasi dan diuji kemaknaannya dengan korelasi Spearman dengan menggunakan program SPSS 2.2.

Fraktur maksilofasial dinilai dari jenis dan jumlah fraktur dibandingkan dengan pola kesadaran pasien yang dinilai berdasarkan GCS. Variabel bebas ialah fraktur maksilofasial dan nilai GCS sebagai variabel tergantung.

\section{HASIL PENELITIAN}

Karakteristik subyek dengan fraktura maksilofasial ialah pada kisaran usia 16-50 tahun (rerata 29,06 $\pm 9,55843$ ). Tabel 1 memperlihatkan dari 50 pasien cedera maksilofasial terdapat 19 pasien cedera ringan, 25 pasien cedera sedang, dan 6 pasien cedera berat.

Tabel 1. Karakteristik subyek berdasarkan jenis fraktur maksilofasial

\begin{tabular}{ccc}
\hline Jenis fraktur & Frekuensi & \% \\
\hline Ringan & 19 & 38,0 \\
Sedang & 25 & 50,0 \\
Berat & 6 & 12,0 \\
Total & 50 & 100,0 \\
\hline
\end{tabular}

Tabel 2 memperlihatkan terdapat 13 pasien $(26,0 \%)$ yang disertai lesi intrakranial dan yang tanpa lesi intrakranial sebanyak 37 pasien.

Tabel 3 memperlihatkan terdapatnya peningkatan persentase adanya lesi intrakranial dengan bertambah parahnya fraktur masilofasial dari 17,9\% pada fraktur ringan sampai $83,4 \%$ pada fraktur berat. Hasil uji statistik mendapatkan nilai $X^{2}$ $32,60 \quad(P<0,0001)$ yang menunjukkan terdapat hubungan bermakna antara derajat 
fraktur maksilofasial dengan lesi intrakranial.

Tabel 4 memperlihatkan jumlah pasien fraktur maksilofasial dengan lesi intrakranial sebanyak 13 pasien. Di antaranya, 4 pasien dengan epidural hematoma $(\mathrm{EDH}) ; 7$ pasien dengan intraserebral hematoma (ICH); 1 pasien dengan subdural hematoma (SDH); dan 1 pasien dengan kombinasi EDH dan ICH. Dari data ini dapat disimpulkan bahwa lesi intrakranial yang paling sering menyertai fraktur maksilofasial ialah ICH.

Tabel 2. Karakteristik subyek dengan lesi intrakranial

\begin{tabular}{ccc}
\hline Lesi intrakranial & Frekuensi & \% \\
\hline Ada & 13 & 26,0 \\
Tidak ada & 37 & 74,0 \\
Total & 50 & 100,0 \\
\hline
\end{tabular}

Tabel 3. Hubungan antara fraktur maksilofasial dengan lesi intrakranial

\begin{tabular}{|c|c|c|c|c|}
\hline \multirow{2}{*}{$\begin{array}{c}\text { Fraktura } \\
\text { maksilofasial }\end{array}$} & \multicolumn{2}{|c|}{ Lesi intrakranial } & \multirow[t]{2}{*}{ Total } & \multirow[t]{2}{*}{$\mathrm{X}^{2}$ Test } \\
\hline & $\begin{array}{c}\text { Tanpa lesi } \\
\text { (normal) }\end{array}$ & Dengan lesi & & \\
\hline Mild & $16(82,1 \%)$ & $3(17,9 \%)$ & 19 & $X^{2}=32,60$ \\
\hline Moderate & $20(75 \%)$ & $5(25 \%)$ & 25 & $(P<0,0001)$ \\
\hline Severe & $1(16,6 \%)$ & $5(83,4 \%)$ & 6 & \\
\hline Total & 37 & 13 & 50 & \\
\hline
\end{tabular}

Tabel 4. Fraktur maksilofasial dengan jenis lesi intrakranial

\begin{tabular}{ccccc}
\hline Total & EDH & ICH & SDH & EDH + ICH \\
\hline 13 & 4 & 7 & 1 & 1 \\
$100 \%$ & $30,8 \%$ & $54,0 \%$ & $7,6 \%$ & $7,6 \%$ \\
\hline
\end{tabular}

Gambar 1 memperlihatkan bahwa kasus fraktur tulang wajah bawah dan tengah sebanyak 7 pasien; 1 di antaranya dengan lesi intrakranial, sedangkan 6 lainnya tanpa lesi intrakranial. Kasus fraktur tulang wajah tengah dan atas ditemukan sebanyak 7 pasien; 4 di antaranya dengan lesi intrakranial dan 3 lainnya tanpa lesi intrakranial. Terdapat 1 pasien dengan fraktur tulang wajah atas, bawah, dan tengah yang juga disertai lesi intrakranial.

Gambar 2 memperlihatkan terdapat kasus fraktur maksilofasial tunggal sebanyak 35 pasien, dimana 4 pasien dengan fraktur maksilofasial bawah tanpa lesi intrakanial; 26 pasien dengan fraktur maksilofasial tengah, 5 di antaranya dengan lesi intrakranial; serta 5 pasien dengan fraktur maksilofasial atas, 2 di antaranya dengan lesi intrakranial.

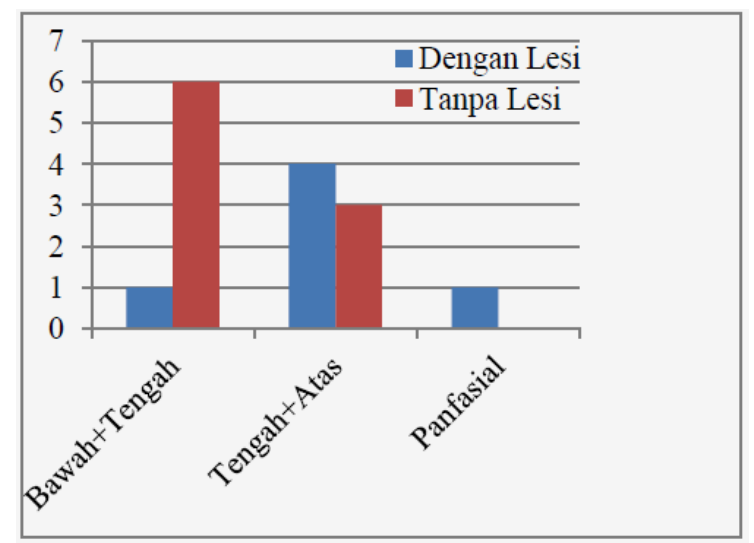

Gambar 1. Fraktur maksilofasial kombinasi 


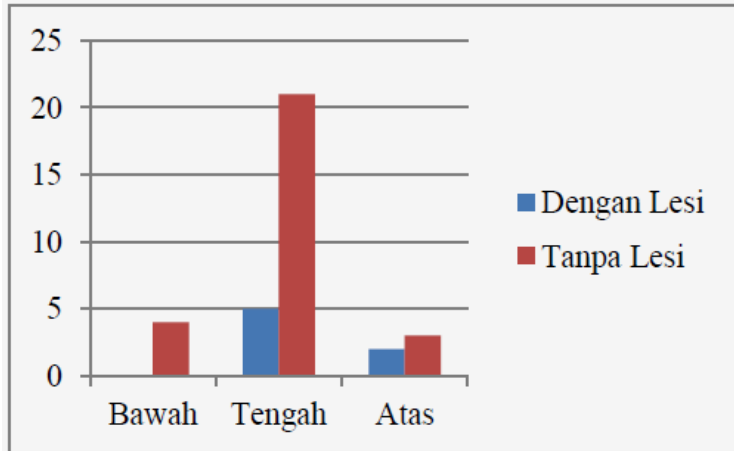

Gambar 2. Fraktur maksilofasial tunggal

\section{BAHASAN}

Fraktur maksilofasial dikelompokkan berdasarkan lokasinya seperti tulang wajah atas meliputi tulang frontal; tulang wajah tengah meliputi tulang zigomatikus dan tulang nasal; tulang wajah bawah tengah meliputi tulang maksilaris dengan klasifikasi Le Fort; serta tulang wajah bawah yaitu tulang mandibula. ${ }^{6}$ Terdapat $76 \%$ pasien dengan trauma maksilofasial datang ke UGD disertai cedera kepala. Hampir seluruh pasien dengan dengan cedera kepala disebabkan oleh kecelakaan di jalan raya. ${ }^{7}$

Sebagian besar pasien pada penelitian ini mengalami fraktur maksilofasial derajat sedang. Hal tersebut sama dengan yang ditemukan pada studi dari Beogo et al. ${ }^{8}$ yang menyimpulkan bahwa kecelakaan pengendara motor menyebabkan trauma maksilofasial derajat sedang (lebih dari 1 garis fraktur). Isik et al. ${ }^{9}$ menemukan bahwa jumlah pasien dengan cedera kepala disertai trauma maksilofasial sebesar $15,44 \%$ (38/246). Sebagian besar pasien dengan fraktur maksilofasial pada studi tersebut terjadi akibat kecelakaan lalu lintas, sehingga lebih banyak pasien dengan fraktur multipel dibanding fraktur tunggal. Hal ini sejalan yang ditemukan Hung et al. ${ }^{10}$ dimana risiko terjadinya lesi intrakranial tidak meningkat pada pasien dengan fraktur tunggal, melainkan pada fraktur multipel termasuk tulang maksila, nasal, dan mandibula.

Fraktur maksilofasial dan lesi intrakranial pada studi ini memiliki hubungan yang sangat kuat dan berarti dimana dari 50 pasien dengan fraktur maksilofasial terdapat 19 pasien dengan fraktur maksilofasial ringan, 25 pasien dengan fraktur maksilofasial sedang, dan 6 pasien dengan fraktur maksilofasial berat. Terdapat perbedaan yang bermakna antara tingkat fraktur maksilofasial dengan tipe lesi intrakranial. Fraktur maksilofasial yang ringan kecil kemungkinannya menyebabkan lesi intrakranial. Hasil uji statistik menggunakan uji $\mathrm{X}^{2}$ untuk menentukan hubungan antara fraktur maksilofasial dan lesi intrakranial pada hasil CT scan memperlihatkan hubungan bermakna antara fraktur maksilofasial dan lesi intrakranial $(P<0,0001)$.

Data ini didukung oleh Goodisson et al. ${ }^{5}$ yang menemukan hasil bermakna dari pasien dengan cedera otak traumatika yang disertai cedera maksilofasial. Dari 2307 pasien yang dirawat dengan cedera kepala traumatika, 5\% di antaranya mengalami cedera maksilofasial. Jenis cedera tulang wajah berhubungan dengan ada tidaknya lesi intrakranial. Pasien dengan fraktur pada tulang wajah bawah (khususnya mandibula), tengah, dan atas tunggal umumnya mengalami cedera otak traumatika ringan $(71 \%, 62 \%$, dan $61 \%$ berurutan). Semua pasien dengan fraktur tulang wajah kombinasi mengalami cedera otak traumatika berat. Dengan bertambahnya keparahan cedera otak traumatika, juga terjadi peningkatan kompleksitas fraktur maksilofasial, serta lokasi dari fraktur (wajah atas dan tengah bawah vs wajah bawah) sehingga dapat disimpulkan bahwa pola fraktur maksilofasial berhubungan dengan keparahan cedera otak traumatika. Pasien dengan fraktur tulang wajah bagian bawah memiliki kemungkinan mengalami cedera otak traumatika ringan. Cedera tulang wajah tengah atau atas lebih mungkin menderita cedera otak traumatika sedang, dan pasien dengan fraktur tulang wajah kombinasi paling memungkinkan mengalami cedera otak traumatika berat.

Patomekanisme terjadinya lesi intrakranial pada fraktur maksilofasial ialah tulang maksilofasial berfungsi sebagai 
bantal pengaman yang melindungi otak dari cedera dan melindungi pengendara kendaraan bermotor saat terjadi kecelakaan lalu lintas, namun efek benturan yang terjadi tetap dihantarkan ke struktur otak. Walaupun tulang maksilofasial meredam kekuatan dari dampak trauma, namun beberapa lokasi fraktur dan mekanisme dari cedera berat dapat memperburuk lesi intrakranial. $^{5}$ Dari hasil penelitian dapat dilihat bahwa terdapat hubungan bermakna antara fraktur maksilofasial dengan nilai GCS. Semakin berat derajat fraktur maksilofasial, semakin besar kemungkinan terdapat penurunan nilai GCS. Dikarenakan bila daya yang terjadi terlalu besar dan melewati batas maksimum maka tetap saja terjadi efek terhadap otak. Dan fungsi dari bantalan pada wajah bermakna sebagai peredam daya bila terjadi suatu benturan pada kepala dalam batas daya tertentu.

\section{SIMPULAN}

Dari hasil penelitian dapat disimpulkan bahwa terdapat hubungan bermakna antara fraktur maksilofasial dan terjadinya lesi intrakranial.

\section{DAFTAR PUSTAKA}

1. Wagner AK, Sasser HC, Hammond FM, Wiercisiewski D, Alexander J. Intentional traumatic brain injury: epidemiology, risk factors, and associations with injury severity and mortality. J Trauma. 2000;49(3):404-10.

2. Yadav SK, Mandal BK, Karn A, Sah AK. Maxilofacial trauma with head injuries at a tertiary care hospital in Chitwan. Turk J Med Sci. 2012;42(2):1505-12.

3. King M, Bewes P. Bedah Primer Trauma (3rd ed). Jakarta: EGC, 2004; p. 137-9.

4. Czerwinski M, Parker WL, Chehade A, Williams HB. Identification of mandibular fracture epidemiology in Canada: Enhancing injury prevention and patient evaluation. Can J Plast Surg. 2008;16(1):36-40.

5. Goodisson D, MacFarlane $M$, Snape $L$, Darwish B. Head injury and associated maxillofacial injury. New Zealand J Med. 2004;117(1201):U1045.

6. Angelopaulos C. Anatomy of the maxilofacial region in the three planes of section. Dent Clin North Am. 2014;58(3):497-521.

7. Yazir S. Facial trauma among patients with head injury. J of IMAB. 2014;20(6):535-8.

8. Beogo R, Dakoure $P$, Savadogo LB, Coulibaly AT, Ouoba K. Associated injuries in patients with facial fractures: a review of 604 patients. Pan African J Med. 2013;16:119.

9. Isik D, Gonullu H, Karadas S, Kocak OF, Keskin S, Garca MF, Eseoglu M. Presence of accompanying head injury in patients with maxillofacial trauma. Turkish J Trauma \& Emerg Surg. 2012;18(3):2006.

10. Hung YC, Montazem A, Castello MA.The correlation between mandible fractures and loss of consciousness. J Oral Maxillofac Surg. 2004;62(8);938-42. 